\title{
Artificial Intelligence in Human Resources Information Systems: Investigating its Trust and Adoption Determinants
}

\author{
B. HMOUD1, L. VARALLYAI2 \\ ${ }_{1}$ University of Debrecen Faculty of Economics and Business, Department of Business Informatics, \\ Bilal.ibrahim.t@gmail.com \\ 2 University of Debrecen Faculty of Economics and Business, Department of Business Informatics \\ varallyai.laszlo@econ.unideb.hu
}

Abstract. With the rapidly emerging trend of employing Artificial Intelligence technologies within modern economics. This study is an attempt to fill the research gap associated with the factors that have influence with the adoption of artificial intelligence in human resources information systems on HR-leaders intention to use it. It empirically investigates the influences that trust, technological readiness, facilitating condition and performance expectancy on HR-professional's behavioral intention to use AI in HRM. Besides, examine the moderating effect of age and experience on the proposed associations. Data were collected from by online questionnaire from $185 \mathrm{HR}$ managers. A structural framework was introduced to test the relationship between study latent variables. Result exhibited that trust and performance expectancy has a significant influence on HR-professionals behavioral intention to use AI-HRIS. Trust and technological readiness showed a significant influence on HR-professionals performance expectancy of using AI-HRIS. While facilitating condition, organizational size and technological readiness did not show a significant influence on HR-professionals behavioral intention toward using AI-HRIS. Lastly, Age and Experience did not have a moderating effect on trust and performance expectancy association with the behavioral intention toward using AI-HRIS. The findings of this study contribute to the theory development of information technology diffusion in HRM.

Keywords: Artificial Intelligence, Human Resources Information systems, Human Resources Management, Information Technology.

\section{Introduction}

Several factors have influenced Human Resources Management (HRM) since its development among which information technology revolution. Starting from the early invention of computers, HRM practices have found its way to utilize these electronic means aiming to increase process efficiency. Therefore, the concept of Human Resources Information System (HRIS) has evolved rapidly gaining organizations and HR leaders interest for its confirmed contribution in cost-saving and competitive 
advantage. It also gains researchers attention as an attempt to assess its actual impact and explain its adoption factors within different business segments. After the invention of the internet, we witnessed the emergence of electronic-Human resources (e-HR) which referred to utilize internet services in conducting HRM [1]. E-HR has significantly contributed to elevating HRM function within the organization giving it more strategic importance. It created an interactive medium that integrates all actors regardless of their geographical allocation and emphasized the HR role by substituting conventional methods into more technologically dependent ones [1]. In addition, while HRIS was mainly oriented to be used by HR personnel within organizations s, e-HR had a major role in including various users and stakeholders into the decision-making process, which have granted HRM an increased strategic contribution. It is argued that nowadays industry 4.0 era is introducing crucial changes to the economics in general and HRM in specific. The rapid advances in technologies as such Artificial Intelligence (AI) are altering jobs and functions leading to an imperative competition and it embodies the future means of business conduct. Consequently, aiming to improve efficacy and quality, HRM has utilized AI-solutions within its processes. Despite the absence of universal agreement, researchers have referred to the AI-based HRIS with several terms among which, Smart Human Resources 4.0 [2], [3], Human Resources Management 4.0 [4] or Intelligent information processing in human resource management [5]. Lately, several AI-based HR solutions have gained increased attention among organizations and HR leaders. These smart HR systems promise solutions that automate time-consuming administrative processes without human intervention. Considering its time-consuming and costly process, recruitment and selection were among the early HR function that has integrated AI within its process. Nowadays, smart systems (e.g. chatbots, search engines) used in sourcing, shortlisting, interacting with job applicants to improve the efficiency of the selection process [6]. It promises a huge advantage in terms of time, cost and human bias, thus HRprofessionals trust is still questionable and needs further investigation.

Technology adoption and application has gained researcher's attention intensively resulting in a variety of technology adoption models such as Technology acceptance model (TAM), Diffusion of Innovation (DIO) and The Unified Theory of Acceptance and Use of Technology (UTAUT). These models aimed to assess the factors that had a significant influence on the user's acceptance and adoption of emerging technologies. While AI in HRIS it promises a major transformation in HRM functionalities in which consistent with industry 4.0 era, researches related to its adoption determinants and HR-professional's attitude toward it scares. This study is an attempt to fill the research gap associated with AI-based HRIS adoption, by assessing a set of selected variables influence on HR-leaders intention to use it. Precisely, in this study empirically investigate the influences that trust, technological readiness, facilitating condition and performance expectancy on HR-professional's behavioural intention to use AI in HRM. Besides, examine the moderating effect of age and experience on the proposed associations. The study objective is to offer increased understanding and insight for HR-leaders, organization and researchers about the determinants of AI-based HRIS adoption. 


\section{Research Model and Hypotheses}

To achieve the study objectives a conceptual structural framework was developed to represent the hypothesized association between the study variables. The study variables are grounded on, UTAUT model [7] with Trust and technological readiness. Figure 1. Illustrate the study variables and the hypothesized relations.

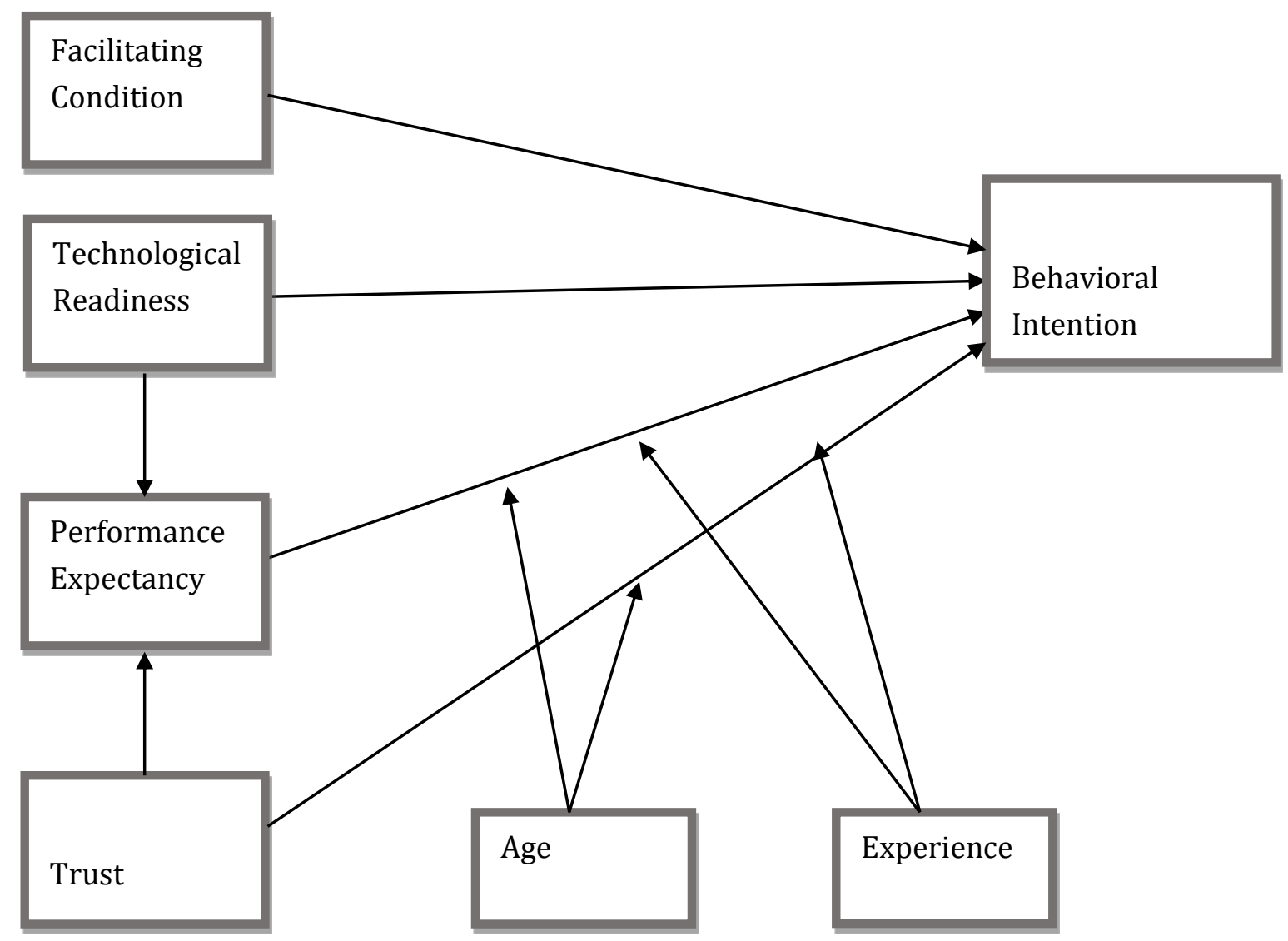

Figure 1. Study framework

\subsection{Trust}

Trust is defined as the " psychological expectation that a trusted party will not behave opportunistically and the willingness of a party to be vulnerable to the actions of other parties" [8], [9]. For a while, trust construct has been showing up frequently in researches as a strong determinant of technology adoption, yet after the invention of internet which led to the emergence of e-business and the rapid technology advancement, trust started to get an increased attention and alignment [10], [11]. Although many theories have been introduced in relation to trust, for this study we reflected earlier researches well-supported conceptualization of trust within technology adoption context. Mayer et al., (1995) model of organizational trust has been frequently appearing in the literature [11]-[14] o explain the perception of trustworthiness within organization behavior and 
technology trust research. It emphasized three dimensions of trusting beliefs, integrity, competence and benevolence. Integrity is associated with trustor perception about trustee adherence to commonly accepted principles, In other words, the trustee would act honestly, keep his promises act ethically and uphold rules [11], [13]. Competence is the belief that the trustee party has the ability, skills and characteristics to deliver on expectations [9], [10]. Benevolence is the extent to which perceptions that trustee is believed be good for the trustor. It is the general perceptions of good intention, the desire to do good [9], [10].

To reflect the sub-constructs on the study context, for instance, we consider the candidate screening process in which AI-based HRIS promises to reduce administrative tasks as well as human bias involved. it's important that HR professionals benevolence that AI-based systems operates for the best interest and provides a great value for HRM objectives within the organization to perceive it more trustworthy. Furtherly, their belief about the system competence means their perception that it is a quality solution to minimize time-consuming and human errors in repetitive tasks and it is capable and proficient to deliver the expected results. Integrity would focus on HR professionals beliefs about these systems providers' ethical obligations such as to secure information privacy issues. This is an important matter when it comes to its adoption since these AI-based systems are mostly web-based, having a trust in the provider's commitment to protecting the organization interests is crucial.

Researches have considered trust as a significant determinant in assessing technology and innovation adoption factor such as e-commerce [11], [12], [15], [16], e-learning [17] nd others. Besides its association with the user intention to adopt new technology, it's argued that trust in an introduced technology or innovation is relatively positively related to its performance expectation or perceived usefulness [12], [15]. he premises behind this assumption is that trust frame a subjective assurance that surge trustee belief in system usefulness and performance expectancy. Thus, we hypothesize that:

H1: Trust has a significant influence on HR-professional's behavioral intentions toward using AIbased HRIS.

H2: Trust has a significant influence on HR-professional's performance expectation of AI-based HRIS.

\subsection{Organizational Size}

Organizational size is one of the most frequently confirmed determinants of IT and innovation adoption (Oliveira and Martins, 2010). Strohmeier and Kabst (2009) proposed that when it comes to the determinant of adoption, the only consistent result is the organizational size. Moreover, many studies (Wang et al., 2016; Wang et al., 2010; Low et al., 2011; Zhu et al., 2003) have found that organizational size has a significant positive relation with IT innovation adoption. Larger organizations often have increased financial and non-financial resources that facilitate IT innovations 
adoption, greater flexibility and more capable of bearing the investment risk (Zhu et al., 2003). Moreover, greater need for innovation is typically associated with larger organizations, thus, more advantages of automation (Strohmeier and Kabst, 2009). Referring to Smart HR systems, HR tasks and processes are more intense in a larger organization due to economies of scale (Strohmeier and Kabst, 2009). For instance, if we consider recruitment and selection, the number of vacant positions and job applications are relatively higher in a larger organization and associated with more administrative work throughout the sourcing and screening process. Therefore, investing in Smart HRS that automate such processes might worth to spend, while smaller organizations less intense HR tasks might face difficulties in justifying such investments.

H3: Organizational size has a significant influence on HR-professional's behavioral intentions toward using AI-based HRIS.

\subsection{Facilitating Condition}

The early definition of Facilitating conditions are defined as environmental factors that make an act easy to do [18] Facilitating condition has been considered as an important construct that has a significant impact on individual and organizational technology use intention and decision. Thus, the emphases on behavioral or environmental conditions within technology adoption theories noticeably varied. Within his UTOUT model, Venkatesh et al.,(2003) emphasized that facilitating conditions are the consumers' perceptions of the resources and support available, and it was an intention to represent the aspects of the organizational environment that are designed facilitate the use of technology. Furthermore, they assumed that facilitating conditions enable researchers to assess the influence of environmental or organizational limits, in which includes unanticipated events, time and other restraints, however, not external factors [19]. Again almost a decade later Venkatesh, Thong, \& Xu, (2012) with an updated UTOUT2 Model, they have emphasized facilitating condition as an indicator to the actual use behavior rather than the intention of use. However, when moderated by age and experience. Several studies [17], [19], [21] have incorporated facilitating condition as a potential predictor of advanced technology adoption.

In this study context, we emphasize facilitating condition to represent the necessary resources and knowledge needed to adopt AI-based HRIS. Also essential compatibility with currently in use systems and the available support. Although artificial intelligence in HRM might be perceived as a revolutionary change to the conventional HRM methods and it promises technically efficient solutions in processing HR tasks. HR professionals and organizations might be irresolute to adopt it when the available support and resources dose not facilitate its application.

H4: Facilitating condition has a significant influence on HR-professional's behavioral intentions toward using AI-based HRIS. 


\subsection{Technological Readiness}

Technological readiness refers to the organization technological compatibility with the introduced new technology from two main perspectives. First, is the available infrastructure and the extent it supports the adoption decision. Second, the human resources expertise, competence and the level of technology sophistication within the organization [22], [23]. In other technology adoption models, technical readiness has several synonymous for example technical compatibility. Researchers [22][27] have been considering technology readiness as a significant factor that influences technology innovation decision. However, while infrastructure and expertise previously showed to influence adoption decision, we underemphasized technological readiness as a factor in adopting AI-based HRIS. The observer for emerging AI-based HR and other management solutions can clearly notice that it is mostly cloud-based. The advances in internet connectivity and data storage have created an obvious shift toward cloud services, where service provider mostly carries out data administration and maintenance, thus, it raises the privacy and security concerns. Notably, AI-based HRM solutions fall in this trend where the user is granted access to the service without any undue hardship in terms of technical components. Therefore, in this study, we don't believe that technological readiness is an influential factor when it comes to the intention to use AI-HRIS or its performance expectancy.

H5: Technological readiness has no influence on HR-professional's behavioral intentions toward using AI-based HRIS.

H6: Technological readiness has no influence on HR-professional's performance expectancy of AIbased HRIS.

\subsection{Performance Expectancy (PE)}

Performance expectancy is defined as "the degree to which an individual believes that using the system will help him or her to attain gains in job performance" [7]. It represents user perception that adopting technology or innovation would generate a certain benefit to the targeted function. It's considered the Synonym of perceived usefulness from the technology acceptance model and to relative advantage in the Diffusion of Innovations model [10], [17]. Researchers [7], [20] argued that performance expectancy has consistently shown its strong prediction of adoption intention. in addition, it showed as a predictor for in E-HR adoption [28]. In this study context, performance expectancy represents HR professional's perception about AI-based HR systems benefits and effectiveness to the organization and HR functionalities in case adopted. Accordingly, we hypothesize that:

H7: Performance expectancy has a significant influence on HR-professional's behavioral intentions toward using AI-based HRIS. 


\subsection{Moderating Effects}

\subsubsection{Age and Experience}

In their UTAUT model Venkatesh et al., (2003) argue that some variables may moderate the relationship between performance expectancy and facilitating condition with the behavioral intention and the actual use voluntariness of use, experience, age and gender. However, later with their UTAUT2 proposed Model Venkatesh et al., (2012) have dropped voluntariness of use as a mediator. Experience has a role in formulating a higher level of awareness for users, also depending on the extent of interaction [7]. Therefore, we can assume that more experienced HR professional who had a previous practice and familiarity HRIS in which developed over time will have a more comprehensive understanding and attitude toward the proposed AI-based HRIS. It's argued that that previous experiences will influence several beliefs and, thus, future behavioral performance [29]. Besides, Venkatesh et al., (2012) argued that as experience increases, the attractiveness to use the technology to gain in efficiency or effectiveness will grow. In this context, assume that the accumulated experience of respondents would influence the association between performance expectancy and trust with the adoption behavioral intention.

Several reasons behind researchers consideration of age as a mediator, among which is that older users face more difficulty in learning of new technologies [20]. In addition, conformity with the used methods and higher resistance to change. Further, older while older users tend to place greater importance adequate support [20], we believe this will also apply on trusting new technology that is still at the diffusion phase. Moreover, it is argued that age is associated with technology innovation. where younger tend to exhibit more interest in new technologies and "a greater tendency to seek novelty and innovativeness" [20].

H8a: The influence of Trust on behavioral intention will be moderated by age, and experience, particularly Youngers, and more experienced HR-Professionals.

$\boldsymbol{H} \boldsymbol{8 \boldsymbol { b }}$ : The influence of performance expectancy on behavioral intention will be moderated by age, and experience, particularly Youngers, and more experienced HR-Professionals.

\subsection{Behavioral Intention (BI)}

Behavioral Intention is defined as "the degree to which a person has formulated conscious plans to perform or not perform some specified future behavior" [30]. In other words, it means it reflects the intention of the adopter if the decision and resources are granted. BI has been used broadly to predict IT use Venkatesh et al., (2003) argued that BI is the most significant predictor of IT adoption and it has been broadly used to predict the use of IT innovation within a variety of context. Fatherly, it is useful to predict adoption behavior when the observed technology is still in its early diffusion phase. Conversely, in case of widely adopted technologies, scholars would use the actual adoption behavior to assess the determinants or the factors with a significant effect on adoption decision. Since AI-based 
HRIS are still in the early diffusion phase, this study uses BI to capture the HR professional's attitude towards adopting AI in human resources management and assess its association with proposed independent variables.

\section{Methods}

\subsection{Participants and procedures}

Electronic survey methodology was used to empirically investigate the study hypothesizes relationships. The survey was carried out in the English language with assured confidentiality and the sample included members of the Jordanian Human Resources Management Association. After obtaining members list from online sources in which includes positions and contact information, our focus was directed toward members with senior positions that include decision-making authority or may have a direct influence on technology adoption decision (e.g. HR Manager, HR Head,... etc.). An e-mail link to the survey along with a cover letter that elaborates about study purpose was sent to a convenient sample of 192 members who participated in this study. Yet, 184 responses were retained after the validation process, resulting in eliminating eight responses for major errors or incomplete data.

\begin{tabular}{|l|l|l|l|}
\hline Variables & Indicators & Measure & Sources \\
\hline Experience (EX) & 1 & Multi-items Liker Scale & [31] \\
\hline AGE (AGE) & 1 & Multi-items Liker scale & \\
\hline Organizational Size (SIZE) & 1 & Multi-items Liker Scale & {$[32]$} \\
\hline Facilitating Condition (FC) & 3 & Multi-items Liker Scale & {$[32],[33]$} \\
\hline Technological Readiness (TR) & 3 & Multi-items Liker Scale & {$[32],[34]$} \\
\hline Performance Expectancy (PE) & 5 & Multi-items Liker Scale & {$[7]$} \\
\hline Trust (TST) & 4 & Multi-items Liker scale & {$[10],[16]$} \\
\hline Behavioral Intention (BI) & 3 & Multi-items Liker Scale & {$[7]$} \\
\hline
\end{tabular}

Table I. Study Measurement Items

\subsection{Instrument}

The study variables are shown in Table. I. Variables were obtained from preceding studies connected to IT innovation adoption, thus their validity and reliability have been demonstrated. However, measurement items were slightly modified to fit the research context. Experience (EX) was measured by years in HRM and working with HRIS. To measure AGE (AGE) one indicator is used where five defined age categories are presented. Organizational Size (SZIE) was measured based on the number 
of employees in the organization., Performance Expectancy (PE), Behavioral Intention (BI) and Facilitating Condition (FC) are based on Venkatesh et al., (2003) The Unified Theory of Acceptance and Use of Technology (UTAUT). Measurement items for Technological Readiness (TR) and Trust (TRT) were drawn from previous studies in which related to technology adoption.

\subsection{Analysis and Results}

To empirically test the proposed model, we employ a variance-based structural equation modelling (SEM) technique processed using the partial least squares (PLS). PLS offers the possibility to perform path-analytic modelling with latent variables [35] and has become popular and commonly used method for estimating complex path models with latent variables including relationships and latent variables with a single indicator [36]. We have selected this method because it is considered an effective technique when dealing with minimal demand on measurement scale, relatively small sample size and residual distribution [35]-[37]. In addition, PLS is adequate to use in the early stage of theory building and testing [15] and has been proven in business research and researchers have utilized it to asses IT innovation adoption [28], [38]-[40]. The analysis of the structural framework was performed using SmartPLS version 3.0 in two stages. First, validate the scales and verify the measurement, confirmatory factor analysis was conducted to assess the validity and reliability of the theoretical constructs. Second, the structural equation model to assess the hypothesized relationships between the latent variables.

\section{Estimates}

\begin{tabular}{|c|c|c|c|c|c|}
\hline Constructs & Indicators & loadings & $\begin{array}{l}\text { Cronbach's } \\
\text { Alpha }\end{array}$ & $\begin{array}{l}\text { Composite } \\
\text { Reliability } \\
\text { (CR) }\end{array}$ & $\begin{array}{l}\text { Average } \\
\text { Variance } \\
\text { Extracted } \\
\text { (AVE) }\end{array}$ \\
\hline \multirow{3}{*}{ Facilitating Condition (FC) } & FC1 & 0.807 & \multirow{3}{*}{0.795} & \multirow{3}{*}{0.875} & \multirow{3}{*}{0.700} \\
\hline & $\mathrm{FC} 2$ & 0.881 & & & \\
\hline & FC3 & 0.820 & & & \\
\hline \multirow{3}{*}{ Technological Readiness (TR) } & TR1 & 0.949 & \multirow{3}{*}{0.909} & \multirow{3}{*}{0.943} & \multirow{3}{*}{0.847} \\
\hline & TR2 & 0.960 & & & \\
\hline & TR3 & 0.848 & & & \\
\hline \multirow{4}{*}{ Trust (TST) } & TRST1 & 0.848 & \multirow{4}{*}{0.839} & \multirow{4}{*}{0.892} & \multirow{4}{*}{0.673} \\
\hline & TRST2 & 0.832 & & & \\
\hline & TRST3 & 0.807 & & & \\
\hline & TRST4 & 0.794 & & & \\
\hline \multirow{3}{*}{ Performance Expectancy (PE) } & PE1 & 0.826 & \multirow{3}{*}{0.890} & \multirow{3}{*}{0.919} & \multirow{3}{*}{0.694} \\
\hline & PE2 & 0.851 & & & \\
\hline & PE3 & 0.849 & & & \\
\hline
\end{tabular}




$\begin{array}{lllllll} & \text { PE4 } & 0.800 & & & & \\ & \text { PE5 } & 0.839 & & & \\ & \text { BI1 } & 0.967 & & & \\ \text { Behavioral Intention (BI) } & \text { BI2 } & 0.914 & 0.943 & 0.963 & 0.898 \\ & \text { BI3 } & 0.961 & & & \end{array}$

Table. II Reliability and Validity measures

\subsection{Measurement of Reliability and Validity}

The framework internal consistency was assessed by validating variables reliability and validity. Firstly, we examine the reliability and convergent validity, a Confirmatory Factor Analysis (CFA) were executed to extract the factor loading of each observed indicators on their underlying observed latent variable. Researchers suggested that Cronbach's $\alpha$ to be higher than 0.7 Composite Reliability (CR) 0.8 and 0.5 for Average Variance Extracted (AVE) [41]. The results illustrate that (see Table .II) all indicators Cronbach's, $\alpha, C R$ and AVE exceeded the thresholds of $0.7,0.8$ and 0.5 consequently without exceptions. Secondly, indicators Loadings were tested against the value 0.7 [42], n result, all standard loadings showed to be higher than 0.7 assuming construct internal consistency, reliability and convergent validity are established. Lastly, Fornell \& Larcker, (1981) test were applied to evaluate the framework discriminate validity. The AVEs square root of each latent variable was compared its correlation with other variables. Results show (Table .III) that the square root of AVE exceeded the correlations for each latent variable meeting Fornell \& Larcker's validity test and proving discriminant validity.

\begin{tabular}{llllllll}
\hline Construct & (AGE) & (BI) & (EX) & (FC) & (PE) & (SIZE) & (TR) \\
\hline Age (AGE) & 1 & & & & & & \\
Behavioral intention (BI) & -0.005 & 0.947 & & & & & \\
Experience (EX) & 0.76 & 0.036 & 1 & & & & \\
Facilitating Condition (FC) & 0.026 & 0.258 & 0.016 & 0.837 & & & \\
Performance Expectancy (PE) & -0.048 & 0.666 & -0.052 & 0.338 & 0.833 & & \\
Organizational Size (SIZE) & 0.244 & -0.021 & 0.327 & 0.156 & 0.003 & 1 & \\
Technological Readiness (TR) & -0.122 & 0.124 & -0.103 & 0.504 & 0.181 & 0.168 & 0.921 \\
Trust (TRST) & -0.1 & 0.634 & -0.115 & 0.313 & 0.777 & -0.01 & 0.122 \\
& \multicolumn{7}{c}{ Table III. Correlation Matrix } \\
\end{tabular}

\subsection{Structural Model and Hypothesis Testing}

The structure Model and proposed association between latent variables were tested using SmartPLS 3.0. A bootstrap with 1000 samples was executed. Summarized in Table V, The path coefficients 
ranged from -0.06 indicated the non-significant association between organizational size and behavioral intention to 0.415 recorded for the significant association between performance expectancy and behavioral intention. Among the eight proposed hypotheses, H1, H2, H5 and H7 are supported, while H3, H4, H6 and H8 are rejected. Among the structural framework variables, only trust and performance expectancy showed a significant influence at $p=0.000$ level on HRprofessionals behavioral intention to use AI-HRIS. Facilitating condition, organizational size and technological readiness did not show a significant influence at $\mathrm{p}=0.05$ level on HR-professionals behavioral intention toward using AI-HRIS. Additionally, trust and technological readiness showed a significant influence at $\mathrm{p}=0.000$ and $\mathrm{p}=0.05$ level respectively on HR-professionals performance expectancy of using AI-HRIS. Lastly, Age and Experience did not have a moderating effect on trust and performance expectancy association with the behavioral intention toward using AI-HRIS.

\begin{tabular}{|c|c|c|c|c|}
\hline \multirow[t]{2}{*}{ Constructs } & $\begin{array}{l}\text { Performance } \\
\text { (PE) }\end{array}$ & Expectancy & $\begin{array}{l}\text { Behavioral } \\
\text { (BI) }\end{array}$ & Intention \\
\hline & Path coeff. & t-value & Path coeff. & t-value \\
\hline Facilitating Condition (FC) & & & 0.016 & 0.226 \\
\hline Organizational Size (SIZE) & & & -0.060 & 0.835 \\
\hline Technological Readiness (TR) & 0.087 & $1.967^{* *}$ & 0.021 & 0.276 \\
\hline Trust (TST) & 0.766 & $16.61^{* * *}$ & 0.310 & $3.515^{* * *}$ \\
\hline Performance Expectancy (PE) & & & 0.415 & $4.489^{* * *}$ \\
\hline \multicolumn{5}{|l|}{ Moderating effects } \\
\hline Age (AGE) - Performance Expectancy & & & -0.008 & 0.057 \\
\hline Experience (EX) - Performance Expectancy & & & 0.013 & 0.092 \\
\hline Age (AGE) - Trust & & & 0.039 & 0.285 \\
\hline Experience (EX) - Trust & & & -0.033 & 0.288 \\
\hline Notes: ${ }^{* *} \mathrm{p}<0.05,{ }^{* * *} \mathrm{p}<0.001$ & & & & \\
\hline
\end{tabular}

\section{Discussions}

This study aims to measure the influence that trust and other factors have in HR-professionals attitude and intention to use the HR systems that employ artificial intelligence. The study proposed a structural framework to empirically test the association between its latent variables. Findings have provided significant insight into the association relationship between trust, facilitating condition, organizational size, technological readiness, performance expectancy and behavioral intention to use AI-HRIS. In addition, the study investigated the moderating effect of age and experience. Generally, it is noticeable that the study participants had a positive expectation and intention to use these smart 
systems. The result of this study support previous empirical evidence [8], [16], [17], [44], [45] that trust has a significant positive association with the user's expectations and intentions toward technology innovation or new technological solutions. However, that evidence highlighted that this trust is developed over time, and it is more possible to be nurtured within user psychology during advanced adoption phases. Despite that artificial intelligence business information systems are relatively in its early diffusion phase, respondents did show a marginal trust notwithstanding they have not used it yet. This can be explained by the reduced time-span that technology diffusion used to require. Due to the increased competitiveness and the rapid technology invention, modern technologies are moving too fast leavening no much time for organizations and reducing diffusion phase substantially. For instance, from $3 \mathrm{G}$ to $4 \mathrm{G}$ and now countries and companies are competing to have the lead in next-generation 5G. Another explanation is that the increased connectivity, data storage and the wide speared of AI applications within different areas (e.g. spontaneous cars, social media) enforce the general trusting attitude toward AI. This can also explain that age and experience did not have a moderating effect with trust since the engagement with these AI-based social media is wide among all levels of experience and age categories.

In contrary with important previous studies, organizational size did not show to have a significant influence on HR-professionals intention to use AI-based HRIS. This result can be explained by two elements. First is that the selection of the study sample was driven to be HR-professionals with authorities within the organization. Thus, the study did not have a specific targeted organizational size such as (SMEs) or large-size organization. This fact might contributed in lessening organizational size importance to the study results. Second, the fact the study considered employees count as an indicator of organization size could have a role in neglecting these results. Despite that, some of the early technology adoption studies have considered employees count to indicate organization size; however, recent indication argues that financial capital and market share are better indicators. The atomization, modern IT advancements and AI technologies have enabled organizations to extraordinarily reduce their dependence on human resources. For instance, especially within the information technologies industries, companies with leading worldwide income have only several hundred employee or less. This indicates that researchers should reconsider the conventional methods to assess organizations size to include ones that are more reflective. Although earlier studies of HRIS and E-HR [46], [47], as well as other IT innovation adoption [22], [24], [25], [27] emphasized technological readiness and compatibility as significant determinants of adoption behavior. This study results showed that technological readiness had no influence on the intention to use AI-HRIS, which Confirms our hypothesis. This supports our claim that AI-systems and the prevailing trend in the IT industry and 4.0 era is heading toward cloud computing. The rapid advancement in connectivity and data storage capability have enabled service providers to lessen the significance of the user's technical readiness. The vast majority of AI-based systems (e.g. recruitment Chatbots, search engines) are cloud-based services that can be configured with the user's website or systems. Furtherly these results confirm [22] result where technological readiness didn't show an influence on cloud-computing adoption. in contrary, Wu, Cegielski, Hazen, \& Hall, (2013) showed a negative 
association between technical compatibility and behavioral intention of cloud computing. Thus, our result indicated that technological readiness showed a significant influence on the respondent's performance expectancy..

Rejecting our hypothesis, facilitating condition did not show a significant influence on HRprofessional's intention to use AI HR solutions. This result contradicts with [19], [20] in which facilitating condition counted as a significant determinants. However it is in line with [17], [21] which examine the intention to use e-learning technology. Supporting our hypothesis, performance expectancy has shown to has the strongest significant positive influence at $\mathrm{p}=0.000$ level on HRprofessionals intention to use artificial intelligence in HRM. The study result confirms [20], [49] argument that performance expectancy has consistently shown to be one of the strongest predictors of behavioral intention to adopt information technology within technology adoption research. Additionally, the study support [28] results in which revealed a strong positive relationship between performance expectancy and participants intention to adopt e-HR.

\section{Conclusions}

The studies that tackled the artificial intelligence applications in human resources management scares. Especially the phenomenon of its adoption factors and HR-professional's attitude toward its use. The findings of this study is an attempt to contribute to the theory development of information technology adoption in HRM. The study revealed that HR-professionals possess a positive attitude and trust toward the new emerging technologies in which it applies AI methods to support HRM effectiveness within organizations and its potential to elevate quality. In addition, and in contrary to earlier HRIS applications, we concluded that the significance of technical readiness and facilitating condition as an adoption determinants is diminishing. Further, the study showed that age and experience had no role as a mediator effect on the intentions to use, which indicate that the earlier gaps in different age groups attitude toward technology is also diminishing. While it is believed that

AI technology is expected to have the focus of future research and investments, and it will majorly contributes in reshaping business processes, organization and HR-leaders are encouraged to follow up on research and explore its potential effect on HR practices.

\section{References}

[1] S. Strohmeier, "Research in e-HRM: Review and implications," Hum. Resour. Manag. Rev., vol. 17, no. 1, pp. 19-37, 2007.

[2] B. Sivathanu and R. Pillai, "Smart HR 4.0 - how industry 4.0 is disrupting HR," Hum. Resour. Manag. Int. Dig., vol. 26, no. 4, pp. 7-11, 2018.

[3] S. Shamim, S. Cang, H. Yu, and Y. Li, "Management Approaches for Industry 4.0," Evol. Comput. (CEC), 2016 IEEE Congr., pp. 5309-5316, 2016. 
[4] L. B. Liboni, L. O. Cezarino, C. J. C. Jabbour, B. G. Oliveira, and N. O. Stefanelli, "Smart industry and the pathways to HRM 4.0: implications for SCM," Supply Chain Manag., vol. 24, no. 1, pp. 124-146, 2019.

[5] L. Zhang and W. Hong, "Intelligent information processing in human resource management: an implementation case in China," Expert Syst., vol. 23, no. 5, pp. 356-369, 2006.

[6] B. HMOUD and V. LASZLO, "Will Artificial Intelligence Take Over Human Resources Recruitment and Selection?," Netw. Intell. Stud., vol. VII, no. 13, pp. 21-30, 2019.

[7] V. Venkatesh, M. G. Morris, G. B. Davis, and F. D. Davis, "USER ACCEPTANCE OF INFORMATION TECHNOLOGY: TOWARD A UNIFIED VIEW," vol. 27, no. 3, pp. 425-478, 2003.

[8] G. Kim, B. Shin, and H. G. Lee, "Understanding dynamics between initial trust and usage intentions of mobile banking," Inf. Syst. J., vol. 19, no. 3, pp. 283-311, 2009.

[9] R. C. . Mayer, J. H. Davis, and F. . D. Schoorman, "An Integrative Model of Organizational Trust Author," Acad. Manag. Rev., vol. 20, no. 3, pp. 709-734, 1995.

[10] T. Casey and E. Wilson-Evered, "Predicting uptake of technology innovations in online family dispute resolution services: An application and extension of the UTAUT," Comput. Human Behav., vol. 28, no. 6, pp. 2034-2045, 2012.

[11] D. H. Mcknight and N. L. Chervany, "What Trust Means in E-Commerce Customer Relationships : An Interdisciplinary Conceptual Typology Relationships: Typology An Interdisciplinary Conceptual," Int. J. Electron. Commer., vol. 6, no. 2, pp. 35-59, 2002.

[12] D. Gefen, E. Karahanna, and D. W. Straub, "Trust and TAM in Online Shopping: An Integrated Model," MIS Q. Manag. Inf. Syst., vol. 27, no. 1, pp. 51-90, 2003.

[13] A. M. Evans and W. Revelle, "Survey and behavioral measurements of interpersonal trust," J. Res. Pers., vol. 42, no. 6, pp. 1589-1597, 2008.

[14] D. Gefen, "Reflections on the Dimensions of Trust and Trustworthiness among Online Consumers," Database Adv. Inf. Syst., vol. 3, no. 3, pp. 38-53, 2002.

[15] X. Luo, H. Li, J. Zhang, and J. P. Shim, "Examining multi-dimensional trust and multi-faceted risk in initial acceptance of emerging technologies: An empirical study of mobile banking services," Decis. Support Syst., vol. 49, no. 2, pp. 222-234, 2010.

[16] D. H. McKnight, V. Choudhury, and C. Kacmar, "Developing and validating trust measures for ecommerce: An integrative typology," Inf. Syst. Res., vol. 13, no. 3, pp. 334-359, 2002.

[17] M. El-Masri and A. Tarhini, "Factors affecting the adoption of e-learning systems in Qatar and USA: Extending the Unified Theory of Acceptance and Use of Technology 2 (UTAUT2)," Educ. Technol. Res. Dev., vol. 65, no. 3, pp. 1-21, 2017. 
[18] R. L. Thompson, C. A. Higgins, and J. M. Howell, "Personal computing: Toward a conceptual model of utilization," MIS Q. Manag. Inf. Syst., vol. 15, no. 1, pp. 125-142, 1991.

[19] S. Moghavvemi, N. A. Mohd Salleh, and C. Standing, "Entrepreneurs adoption of information system innovation: The impact of individual perception and exogenous factors on entrepreneurs behavior," Internet Res., vol. 26, no. 5, pp. 1181-1208, 2016.

[20] V. Venkatesh, J. Y. L. Thong, and X. Xu, “CONSUMER ACCEPTANCE AND USE OF INFORMATION TECHNOLOGY: EXTENDING THE UNIFIED THEORY OF ACCEPTANCE AND USE OF TECHNOLOGY," Forthcom. MIS Q., vol. 36, no. 1, pp. 157-178, 2012.

[21] T. Teo, "Examining the intention to use technology among pre-service teachers: An integration of the Technology Acceptance Model and Theory of Planned Behavior," Interact. Learn. Environ., vol. 20, no. 1, pp. 3-18, 2012.

[22] C. Low, Y. Chen, and M. Wu, "Understanding the determinants of cloud computing adoption," Ind. Manag. Data Syst., vol. 111, no. 7, pp. 1006-1023, 2011.

[23] K. Zhu, K. L. Kraemer, and S. Xu, "The process of innovation assimilation by firms in different countries: A technology diffusion perspective on e-business," Manage. Sci., vol. 52, no. 10, pp. 1557-1576, 2006.

[24] T. Oliveira and M. F. Martins, "Understanding e-business adoption across industries in European countries," Ind. Manag. Data Syst., vol. 110, no. 9, pp. 1337-1354, 2010.

[25] Y. M. Wang, Y. S. Wang, and Y. F. Yang, "Understanding the determinants of RFID adoption in the manufacturing industry," Technol. Forecast. Soc. Change, vol. 77, no. 5, pp. 803-815, 2010.

[26] M. L. To and E. W. T. Ngai, "Predicting the organisational adoption of B2C e-commerce: An empirical study," Ind. Manag. Data Syst., vol. 106, no. 8, pp. 1133-1147, 2006.

[27] S. Sun, C. G. Cegielski, L. Jia, and D. J. Hall, "Understanding the Factors Affecting the Organizational Adoption of Big Data," J. Comput. Inf. Syst., vol. 58, no. 3, pp. 193-203, 2018.

[28] S. M. Obeidat, "The link between e-HRM use and HRM effectiveness: an empirical study," Pers. Rev., vol. 45, no. 6, pp. 1281-1301, 2016.

[29] I. Ajze and M. Fishbein, "The Influence of Attitudes on Behavior,\|," Handb. Attitudes D. Albarracín, B. T. Johnson, M. P. Zanna (eds.), Mahwah, NJ Erlbaum, no. May, pp. 173-221, 2005.

[30] P. R. Warshaw and F. D. Davis, "Disentangling behavioral intention and behavioral expectation," J. Exp. Soc. Psychol., vol. 21, no. 3, pp. 213-228, 1985.

[31] E. W. T. Ngai and F. K. T. Wat, "Human resource information systems : a review and empirical analysis," vol. 35, no. 3, pp. 297-314, 2006. 
[32] Y. S. Wang, H. T. Li, C. R. Li, and D. Z. Zhang, "Factors affecting hotels' adoption of mobile reservation systems: A technology-organization-environment framework," Tour. Manag., vol. 53, pp. 163-172, 2016.

[33] A. Y. L. Chong and F. T. S. Chan, "Structural equation modeling for multi-stage analysis on Radio Frequency Identification (RFID) diffusion in the health care industry," Expert Syst. Appl., vol. 39, no. 10, pp. 8645-8654, 2012.

[34] T. Oliveira and M. F. Martins, "Information technology adoption models at Firm Level: Review of literature," 4th Eur. Conf. Inf. Manag. Eval. ECIME 2010, no. May, pp. 312-322, 2010.

[35] W. W. Chin, “The Partial Least Squares Approach to Structural Modeling," Mod. Methods Bus. Res., no. November, pp. 295-336, 1998.

[36] M. Sarstedt, C. M. Ringle, and J. F. Hair, Handbook of Market Research, no. September. 2017.

[37] W. Reinartz, M. Haenlein, and J. Henseler, "An empirical comparison of the efficacy of covariance-based and variance-based SEM," Int. J. Res. Mark., vol. 26, no. 4, pp. 332-344, 2009.

[38] A. Popovič, R. Hackney, P. S. Coelho, and J. Jaklič, "Towards business intelligence systems success: Effects of maturity and culture on analytical decision making," Decis. Support Syst., vol. 54, no. 1, pp. 729-739, 2012.

[39] H. F. Lin, "Understanding the determinants of electronic supply chain management system adoption: Using the technology-organization-environment framework," Technol. Forecast. Soc. Change, vol. 86, pp. 80-92, 2013.

[40] B. Puklavec, T. Oliveira, and A. Popovič, "Understanding the determinants of business intelligence system adoption stages an empirical study of SMEs," Ind. Manag. Data Syst., vol. 118, no. 1, pp. 236-261, 2018.

[41] R. Bagozzi and Y. Yi, “On the Evaluation of Structure Equation Models,” no. January, 1988.

[42] D. W. Straub, "Validating instruments in MIS research," MIS Q. Manag. Inf. Syst., vol. 13, no. 2, pp. 147-165, 1989.

[43] C. Fornell and D. F. Larcker, "Structural Equation Models with Unobservable Variables and Measurement Error: Algebra and Statistics," J. Mark. Res., vol. 18, no. 3, p. 382, 1981.

[44] S. K. Lippert and P. M. Swiercz, "Human resource information systems (HRIS) and technology trust," J. Inf. Sci., vol. 31, no. 5, pp. 340-353, 2005.

[45] Y. M. Yusoff, T. Ramayah, and N.-Z. Othman, "Why Examining Adoption Factors, HR Role and Attitude towards Using E-HRM is the Start-Off in Determining the Successfulness of Green HRM?," J. Adv. Manag. Sci., no. December 2015, pp. 337-343, 2015.

[46] T. Teo, G. S. Lim, and S. A. Fedric, "The adoption and diffusion of human resources information systems in Singapore," Asia Pacific J. Hum. Resour., vol. 45, no. 1, pp. 44-62, 2007. 
[47] I. Troshani, C. Jerram, and S. R. Hill, "Exploring the public sector adoption of HRIS," Ind. Manag. Data Syst., vol. 111, no. 3, pp. 470-488, 2011.

[48] Y. U. N. Wu, C. G. Cegielski, B. T. Hazen, and D. J. Hall, “CLOUD COMPUTING IN SUPPORT OF SUPPLY CHAIN INFORMATION SYSTEM INFRASTRUCTURE : UNDERSTANDING WHEN TO GO TO THE CLOUD," in Fifteenth Annual Conference of the Southern Association for Information Systems, 2013, no. July, pp. 25-41.

[49] V. Venkatesh, J. Y. L. Thong, and X. Xu, "Unified theory of acceptance and use of technology: A synthesis and the road ahead," J. Assoc. Inf. Syst., vol. 17, no. 5, pp. 328-376, 2016. 